\title{
XXV. Observations on the supposed vision of the blood-vessels of the eye
}

\author{
Sir David Brewster L.D.D. F.R.S.
}

To cite this article: Sir David Brewster L.D.D. F.R.S. (1834) XXV. Observations on the supposed vision of the blood-vessels of the eye , Philosophical Magazine Series 3, 4:20, 115-120, DOI: $10.1080 / 14786443408648275$

To link to this article: http://dx.doi.org/10.1080/14786443408648275

册 Published online: 01 Jun 2009.

Submit your article to this journal $₫$

Џll Article views: 3

Q View related articles $๘$ 
XXV. Observations on the supposed Vision of the Blood-vessels of the Eye. By Si R David Brewsiter, L.L.D., F.R.S.*

IN the Number of this Journal for September 1832, I had occasion to refer to the remarkable experiment described by Dr. Purkinje of Breslau, in which the blood-vessels of the retina are supposed to be exhibited; and though $I$ had in vain tried to see this phænomenon, yet it had been so accurately described to me by Mr. Potter that I ventured to give an opinion respecting its cause. The paper which contained this explanation was read at the Physical section of the British Association at Oxford in June 1832, and Mr. Wheatstone, who was present, favoured the Meeting with some excellent observations on the subject. 'These observations have been printed in the Report of the Association for 1832, in the form of an Appendix to the abstract of my paper; and as they are highly interesting, and will form the groundwork of the following observations; I shall give them verbatim.

"After the reading of Sir David Brewster's paper, Mr. Wheatstone said, that having been the first person to introduce Purkinje's beautiful experiment into this country, and having repeated it a great number of times under a variety of forms, he would take the opportunity of stating a few particular's respecting it, which appeared not to be generally known. The experiment succeeds best in a dark room, when, one eye being excluded from the light, the flame of a candle is placed by the side of the unshaded eye, but so as not to occupy any of the central part of the field of view. So long as the flame of the candle remains stationary, nothing further occurs than a diminution of the sensibility of the retina to light; but after the flame has been moved upwards and downwards, through a small space, for a length of time, varying with the susceptibility of the individual on whom the experiment is tried, the phænomenon presents itself. The blood-vessels of the retina, with all their ramifications, exactly as represented in the engravings of Sœmmerring, are distinctly seen, apparently projected on a plane before the eye, and greatly magnified. The image continues only while the flame is in motion : directly, or soon after, the flame becomes stationary, it dissolves into fragments and disappears.

“ Mr. Wheatstone dissented from the ingenious explanation of this appearance offered by Sir David Brewster, and also from that opinion stated to be the generally received one; and begged to repeat the solution he had published, and which he had not since been induced to relinquish. Mr. W. observed, that there was no difficulty in accounting for the image; it evidently was a shadow resulting from the obstruction of light by the bloodvessels spread over the retina; the real difficulty was to explain why this shadow is not always visible. To account for this, $\mathrm{Mr}$. W. adduced several facts, which tended to prove that an object, either more or less luminous than the ground on which it is placed, when continuously presented to the same point of the retina, becomes invisible; and the rapidity of its disappearance is greater as the difference of luminous intensity between the object and the ground is less; but by continually shifting the place of the image of the object on the retina, or by making it act intermittently on the same point, the object may be

* See Lond. and Edinb. Phil. Mag., last Number, p. 43, and also vol. i. p. 318. 


\section{Sir D. Brewster's Observations on the supposed}

rendered permanently visible. 'To apply this explanation to the phænomenon in question, Mr. W. observed, that whenever the flame of the candle changes its place, the shadows of the vessels fall on different parts of the retina; which is evident from the motion of the figure while the eye remains still, which is al ways in a contrary direction to that of the flame. Hence the shadow, being thus made to change its place on the retina, remains, according to the law above stated, permanently visible; but instantly the flame is at rest, the shadow also becomes stationary, and consequently disappears.

"Mr. Wheatstone then exhibited an instrument for showing an original variation of this experiment : it consisted of a circular plate of inetal, about two inches in diameter, blackened at its outer side, and perforated at its centre with an aperture about as large as an ordinary gun-hole; to the inuer face was fixed a similar plate of ground glass. On placing the aperture between the eye and the flame of a candle, and keeping the plate in motion, so as to displace continually the image of the aperture on the retina,; the bloud-vessels will be seen distributed as before, but will now appear brighter, and the spaces between the ramifications will be seen filled with innumerable minute vessels, anastomosing with each other in every direction, which were invisible in the former experiment. In the very centre of the field of vision there is a small circular space, in which no traces of these vessels appear. Mr. W. remarked, that the absence of these mi. nute obstructions to light will probably account for the greater distinctness with which sinall objects are there seen, and also for the difference of colour observed by anatomists in that spot of the retina."

In this experiment Mr. Wheatstone has described, 1st, the common method of seeing the blood-vessels, and $2 n d l y$, an original variation of the experiment by which the blood-vessels are seen much more distinctly and completely.

As Mr. Wheatstone was so kind as to lend me, when at Oxford, his plate of metal, \&c., I was enabled to see the very phænomenon which he saw, and I have repeated the experiment fifty times since under many modifications. I have therefore no hesitation in asserting that the ramifications exhibited by Mr. Wheatstone's apparatus are not blood-vessels, but are nothing more than the ramifications described in my paper already referred to (Lond. and Edinb. Phil. Mag., vol. i. p. $170 . \oint .1$.). If we throw aside the ground glass in Mr. Wheatstone's apparatus, and look at a luminous surface through the circular aperture when moved as he describes, the same phænomenon will be seen; and if we substitute a rectilineal aperture, and make the line of motion perpendicular, or nearly so, to its longest sides, the phænomena will be seen still more distinctly; and if we look through one or more narrow slits, as in my experiment, the effect will be the same. In short, the edges of the circular aperture in Mr. Wheatstone's apparatus perpendicular to the line in which the aperture is moved, perform the part of the rectilineal slit or slits in my experiment. Mr. Wheatstone will have no difficulty in recognising the perfect identity of the two experiments, and he will therefore see 
that the ramifications are nothing more than the new forms given to the luminous and dark parallel lines produced by the action of light upon the retina. In order to demonstrate this, let us use Mr. Wheatstone's own apparatus. The general direction of the ramifications is invariably perpendicular to the direction in which the aperture is moved. If we change this direction from a horizontal to a vertical line the ramifications clange their direction also, so that we can give them any inclination we please. They cannot, therefore, be pictures or representations of any blood-vessels in the eye.

This unequivocal result would have induced me to believe that the ramifications seen by the common method had a similar origin, and were owing to the action of the rectilineal sides of the flame upon the retina, had I not succeeded in seeing this phænomenon with my own eyes. At the Observatory of Cambridge, last summer, Sir John Herschel pointed out to Mr. Airy and myself the method by which he saw the ramifications, and we were all successful in observing the same phænomenon. This method scarcely differed from that described by Mr. Wheatstone, but the ramifications which I saw were toto coelo different from those produced by $\mathrm{Mr}$. Wheatstone's apparatus : they had not, indeed, one property in common but that of ramifying. The one was seen with great difficulty and occasionally in the middle of a brownish red light, which did not proceed directly from the candle; while the other was distinctly and continuously seen in the middle of condensed light proceeding directly from the candle or other luminous body.

Regarding, therefore, the phænomenon as real, and the ramifications as occasioned by a blood-vessel of the retina, I shall proceed to examine the different explanations that have been given of it.

The explanation given by Mr. Wheatstone is exceedingly ingenious; and the principle which he lays down, and which is printed in Italics, is in every respect well founded. This property of the retina, by which it is unable to maintain the continued visibility of an object seen obliquely, or at a distance from the axis of vision, was communicated by me to the Royal Society of Edinburgh on the 19th of January 1818, and has since appeared in several elementary works on optics ; and it is a necessary corollary from the law of oblique vision, that any movement of the object must restore its visibility by removing the cause of its disappearance, namely, the continued action of the light upon the retina.

So far, therefore, Mr. Wheatstone's explanation is unimpeachable; but when he states that the motion of the flame 
causes the shadores of the vessels to fall on different parts of the retina, we can no longer follow him. Unless the blood-vessel is placed at a certain distance in fiont of the retina, and consequently in the vitreous humour, it can have no moving shadow; and unless it is within the refracted cone of rays which proceed from the candle, it can have no shadow either moveable or stationary. If the shadow here referred to, be the shadow produced from the direct light of the candle, then the bloodvessel would appear across the visible flame of the candle, and not at the side of it in the reddish brown light. But independent of these objections to the application of the optical principle previously laid down, there are two facts which appear to be conclusive against the explanation: the one is, that the bloodvessels of the retina are not at a distance from it; and the other, that the ramifications may be seen distinctly when the candle is not in motion*. There is one objection more to this explanation, which appears to me a formidable one: the ramifications ought to be distinctly and readily seen when the light which forms the shadow is reduced to the same state of dilution, and the same colour, as the reddish brown light on which they appear. This experiment I have repeatedly made with light of all degrees of dilution and divergency, but $I$ have never been able to see a trace of the ramifications.

If the ramifications in question are the representation of a blood-vessel, it becomes very interesting to ascertain the cause to which their visibility is owing. The first step in the inquiry is obviously to determine the origin of the reddish brown light in which the phænomenon is seen. It is quite clear that the brown light is no part of the cone of refracted rays that proceed from the candle: it is equally clear that it is not produced by two or more reflections from the curved surfaces which bound any of the humours of the eye, because in this case it would be of the same colour with the light of the can-

* The force of this last objection will depend on the circumstances of the case. Mr. Wheatstone says that the image "continues only while the flame is in motion," and that "directly, or soon after, the flame becomes stationary, it dissolves into fragments and disappears." Now if this is a phænomenon of oblique vision, the image ought not to disappear permanently. One part of it should disappear while another part remains visible, and the whole may for a short time continue invisible; but it will soon reappear, because it would require great steadiness, both in the hand and head of the observer, to keep the shadow on the same part of the retina, though even this would not ensure its permanent invisibility. If this, therefore, were a phænomenon of indirect vision, the difficulty would consist in losing sight of the ramifications, whereas the difficulty really consists in seeing them; and this difficulty is so great with me, that 1 have never been able to see them again since 1 saw them at Cambridge. 
dle: and I have besides ascertained that it has no focus; for if it had, it would expand and contract by any variation in the distance of the candle. It cannot proceed from any imperfect transparency in any of the coats or humours of the eye, because it is seen in eyes that have the most pure and perfect vision. It must, therefore, be light produced by a physiological action, or light propagated from, or induced by, the direct image of the candle upon the retina; and if this is the case, the explanation which I formerly gave of the phænomenon is likely to be the true one. The blood-vessels touching the retina will deaden, as it were, the part of the retina which they touch, or make it less sensible to the propagated light, and hence the blood-vessels will appear delineated in a fainter light than that which surrounds them. The distinctness with which the ramifications will thus be seen will vary with the intensity of the brown light, with the ever changing sensibility of the retina, and with the varying pressure of the blood-vessels themselves. If I could command the vision of these ramifications as Mr. Wheatstone can, it would not be difficult to institute experiments by which the preceding explanation could be cross-examined; and I therefore hope that he will resume the subject in reference to the facts and views which $I$ have ventured to state.

Before concluding this notice I may mention, as connected with the subject, some curious phænomena which appear when we throw a condensed beam of light upon the retina so as to fill the whole eye. This may be done by holding near the eye a convex lens, about an inch in diameter, and an inch or so in focal length, so as to see its whole area filled with the light of a candle or lamp. If we move the lens backwards and forwards quickly, looking steadily at one point of the field, we shall see on each side of the axis of vision the ramifications described in my former paper and in the preceding pages. There are none of them visible within a certain space round the axis of vision; but in the axis of vision there is an irregularly illuminated or shaded circular spot, obviously corresponding to the foramen centrale of the retina; and in this spot, and for some distance round it, is seen a sort of network pattern, delineated in dark lines. This pattern* has sometimes all the regularity of one formed geometrically, with dark spots in the centre of each area, and the ground on which the pattern is seen is generally of a faint purple colour. But, what is nore remarkable, the luminous field is crossed by ex-

* The very same phænomenon is seen, though less distinctly, when we look steadily at the moving or flaring summit of the flame of a candle. 
ceedingly faint bands of red and green light perpendicular to the direction of the motion.

When the eye has not been fatigued by light, the luminous ground on which these phænomena are seen has a minutely granular appearance; and by the continued action of the light an apparent effervescence appears over the whole, as if each grain of light, or the minute spaces between the grains, were becoming more or less luminous in succession.

Belleville, Dec. 18, 1833.

XXV1. Descriptions of some nondescript British Species of May-fies of Anglers. By Joн CurTis, Esq, F.L.S., \& c.**

A $\mathrm{S}$ few insects are more remarkable in their œeconomy or A. more employed for the amusement of men than the Ephemera and Phryganida, I hope the characters of some new genera and species may induce others to pay attention to these curious and interesting tribes of insects.

The following descriptions are scarcely more than the essential characters: the numbers refer to Mr. Curtis's Guide to an Arrangement of British Insects, in which a list of the species has been given.

\section{Order NEUROPTERA. Fam. Ephemeride. Gen. 734. Ephemera Linn.}

\section{7. fusca Curt.}

$2 \frac{1}{4}$ lines long : dull piceous, the space between the eyes and the base of the anterior legs ferruginous, the others ochreous; filaments longer than the insect, pale lurid, dotted; the articulations long: wings transparent, superior with few transverse nervures and the longitudinal ones most distinct; inferior very small.

\section{Gen. 735. BaETrS Lea.}

\section{A. The wings very much reticulated.}

2. dispar Curt. Brit. Ent. pl. 484 .

The Pseudimagot of this insect may be the $E$. venosa DeGeer.

7. costalis Curt.

5 lines long: slender, pale castaneous, sides of thorax, apex of abdomen and legs ochreous, the joints of tarsi fuscous at the articulations; filaments very long, pale yellow, each joint with the apex black ; superior wings with the costa brownish yellow.

6. elegans Curt.

4, lines : bright ochre, abdomen inclining to pale chestnut ; filaments whitish dotted with fuscous, tarsi with all the joints tipped with black : wings beautifully opalescent, stained very pale yellowish brown, the costa darker, especially towards the apex.

* Communicated by the Author.

$\uparrow$ By Pseudimago I designate the fourth state of the Ephemeride. 